Research

Open Access

\title{
Cardiac effects of induction agents in the septic rat heart
}

\author{
York A Zausig, Hendrik Busse, Dirk Lunz, Barbara Sinner, Wolfgang Zink and Bernhard M Graf
}

\author{
Department of Anaesthesiology and Critical Care, University of Regensburg, Franz-Josef-Strauss-Allee 11, Regensburg, 93053, Germany \\ Corresponding author: York A Zausig, york.zausig@klinik.uni-regensburg.de
}

Received: 3 Aug 2009 Revisions requested: 28 Aug 2009 Revisions received: 2 Sep 2009 Accepted: 8 Sep 2009 Published: 8 Sep 2009

Critical Care 2009, 13:R144 (doi:10.1186/cc8038)

This article is online at: http://ccforum.com/content/13/5/R144

(c) 2009 Zausig et al.; licensee BioMed Central Ltd.

This is an open access article distributed under the terms of the Creative Commons Attribution License (http://creativecommons.org/licenses/by/2.0), which permits unrestricted use, distribution, and reproduction in any medium, provided the original work is properly cited.

\begin{abstract}
Introduction The current debate about the side effects of induction agents, e.g. possible adrenal suppression through etomidate, emphasizes the relevance of choosing the correct induction agent in septic patients. However, cardiovascular depression is still the most prominent adverse effect of these agents, and might be especially hazardous in septic patients presenting with a biventricular cardiac dysfunction - or so-called septic cardiomyopathy. Therefore, we tested the dose-response direct cardiac effects of clinically available induction agents in an isolated septic rat heart model.

Methods A polymicrobial sepsis was induced via cecal ligation and single puncture. Hearts $(n=50)$ were isolated and randomly assigned to five groups, each receiving etomidate, $\mathrm{s}(+)$-ketamine, midazolam, propofol, or methohexitone at concentrations of $1 \times 10^{-8}$ to $1 \times 10^{-4} \mathrm{M}$. Left ventricular pressure, contractility and lusitropy, and coronary flow were measured. Cardiac work, myocardial oxygen delivery, oxygen

consumption, and percentage of oxygen extraction were calculated.

Results All of the induction agents tested showed a dosedependent depression of cardiac work. Maximal cardiac work dysfunction occurred in the rank order of $s(+)$-ketamine $(-6 \%)$ <etomidate $(-17 \%)<$ methohexitone $(-31 \%)<$ midazolam ($38 \%)<$ propofol (-50\%). In addition, propofol showed a maximum decrease in contractility of $-38 \%$, a reduction in lusitropy of $-44 \%$, and a direct vasodilator effect by increasing coronary flow by $+29 \%$.

Conclusions Overall, this study demonstrates that these tested drugs indeed have differential direct cardiac effects in the isolated septic heart. Propofol showed the most pronounced adverse direct cardiac effects. In contrast, $\mathrm{S}(+)$ ketamine showed cardiovascular stability over a wide range of concentrations, and might therefore be a beneficial alternative to etomidate.
\end{abstract}

\section{Introduction}

Although the ideal induction agent for critically ill patients has not yet been found, there is general agreement that in those patients an induction agent that provides cardiovascular stability upon induction of anesthesia would be first choice. Nevertheless, current guidelines do not recommend one induction agent over another [1,2]. However, there are concerns that non-cardiovascular side effects, such as possible adrenal suppression by etomidate, could compromise critically ill patients and last at least 24 hours [3]. At present the clinical consequences are not clear [4].

However, the most significant adverse effect of induction agents is cardiovascular depression, which has already been well described in healthy animal models and humans after intravenous administration. The degree of negative cardiovas- cular effects depends on dose and speed of administration and appears to vary greatly among the commonly used drugs $[5,6]$. In non-septic patients or experimental settings, clinically available induction agents, such as etomidate, propofol, ketamine, methohexitone or midazolam, show dose-dependent effects $[5,6]$. These effects result from their variable impact on peripheral arteriolar and venous dilation, from direct cardiac depression or both. Surprisingly, direct cardiac effects of induction agents in isolated septic hearts have so far not been systematically evaluated.

The cardiovascular dysfunction in sepsis derives from a reduced systemic vascular resistance typically complicated by decreased cardiac function [1,2]. This cardiac dysfunction the so-called septic cardiomyopathy - is a major contributor to sepsis-related morbidity and mortality $[7,8]$. It affects both

+dLVP/dt: left ventricular contractility; -dLVP/dt: left ventricular relaxation; $\mathrm{DO}_{2}:$ myocardial oxygen supply; LVP: Left ventricular pressure; $\mathrm{MVO}_{2}: \mathrm{myo}^{-}$ cardial oxygen consumption; $\mathrm{pCO}_{2}$ : partial pressure of carbon dioxide; $\mathrm{PO}_{2}$ : and partial pressure of oxygen. 
ventricles in the phases of contraction and relaxation [7-11]. Almost one-fifth of all septic patients with refractory hypotension die because of a low cardiac output deriving from this severe myocardial dysfunction. It is, therefore, the everyday clinical challenge of each intensive care unit physician to sufficiently treat septic patients without further compromising the already reduced function of the septic heart [9]. This mechanical impairment is accompanied by disturbed myocardial metabolism and coronary flow, which influences a balanced myocardial oxygen supply-demand ratio [10].

However, global cardiac mechanical and metabolic effects of these induction agents in septic cardiomyopathy have thus far not been systematically compared in a dose-dependent fashion. There is very little evidence on the direct in vitro effects of these agents on cardiac contractile function in sepsis, and the isolated, dose-dependent effects of these induction agents on myocardial excitability, contractility, coronary flow, and oxygen utilization in a septic heart are still unknown. We used the isolated ex vivo heart model to study the direct cardiac effects in the absence of confounding neurohormonal, metabolic, or systemic factors.

Therefore, the aim of this study was to directly compare electrical, mechanical, and metabolic effects of etomidate, $s(+)$ ketamine, midazolam, propofol, and methohexitone at equimolar concentrations, with special emphasis on their impact on cardiac work.

\section{Materials and methods}

Approval from the Institutional Animal Care Committee of the University of Goettingen was obtained before initiation of this study. All experimental procedures conformed with German animal safety regulations. Fifty male Wistar rats (weighing 245 $\pm 3 \mathrm{~g}$ ) were injected intraperitoneally with $100 \mathrm{mg} / \mathrm{kg}$ ketamine and 2.5 to $5 \mathrm{mg} / \mathrm{kg}$ xylazine hydrochloride. A polymicrobial sepsis was induced via cecal ligation and a single puncture as reported previously in detail [12]. After 20 hours of incubation, hearts were isolated and prepared as has been described in recent reports [13]. All hearts were perfused at a perfusion pressure of $55 \mathrm{mmHg}$ with a modified KrebsRinger's salt solution, which was filtered in-line ( $5 \mu \mathrm{m}$ poresize filter disk, Sigma-Aldrich ${ }^{\circledR}$, Munich, Germany) and had the following composition: $\mathrm{Na}^{+} 140 \mathrm{mM}$; $\mathrm{K}^{+} 4.5 \mathrm{mM}$; $\mathrm{Mg}^{2+} 1.2$ $\mathrm{mM}$; $\mathrm{Ca}^{2+} 2.5 \mathrm{mM}$; Cl-134 mM; $\mathrm{HCO}_{3}^{-1} 15.5 \mathrm{mM} ; \mathrm{H}_{2} \mathrm{PO}_{4}^{-1.2}$ $\mathrm{mM}$; EDTA $0.05 \mathrm{mM}$; glucose $11.5 \mathrm{mM}$; pyruvate $2 \mathrm{mM}$; mannitol $10 \mathrm{mM}$; and insulin $5 \mathrm{U} / \mathrm{L}$. Mean aortic inflow $\mathrm{pH}$, partial pressure of carbon dioxide $\left(\mathrm{pCO}_{2}\right)$, and partial pressure of oxygen $\left(\mathrm{PO}_{2}\right)$ were $7.39 \pm 0.01,36 \pm 1 \mathrm{mmHg}$, and $580 \pm 25$ $\mathrm{mmHg}$, respectively. Perfusate and heart temperature was maintained at $36.9 \pm 0.3^{\circ} \mathrm{C}$ throughout the experiment.

Spontaneous atrial rate, atrio-ventricular conduction time, and systolic left ventricular pressure (LVP) and its derivative were measured as detailed previously [13]. Coronary inflow was measured at constant temperature and under constant pressure of $55 \mathrm{mmHg}$ by a transit-time in-line ultrasound flow meter (Research Flowmeter T106, Transonic Systems, Ithaca, USA). Coronary inflow and outflow (coronary sinus) oxygen tensions $(\mathrm{mmHg})$ were measured discontinuously using a self-calibrating gas analyzer (AVL OMNI ${ }^{\circledR}{ }^{\circledR}$, Roche Diagnostic, Mannheim, Germany). Oxygen delivery, percent oxygen extraction, and myocardial oxygen consumption were calculated as noted previously $[6,13]$. Cardiac work ((left ventricular systolic pressure - left ventricular diastolic pressure) $\times$ heart rate) was calculated [14]. All measurements were taken during the last minute of each 15-minute experimental period for statistical analysis.

The experimental protocol is shown in Figure 1. After steady state, the hearts were randomly assigned by lottery to five groups (10 hearts each) and received propofol (Disoprivan ${ }^{\circledR}$, AstraZeneca, Wedel, Germany), midazolam (Midazolam-Ratiopharm ${ }^{\circledR}$, Ratiopharm, Ulm, Germany), s(+)-ketamine (S(+)Ketamine ${ }^{\circledR}$, Pfizer Pharma, Berlin, Germany), methohexitone (Brevimytal ${ }^{\circledR}$, Hikma Pharma, Graefeling, Germany), or etomidate (Etomidat-Lipuro ${ }^{\circledR}$, B. Braun, Melsungen, Germany). Each heart was perfused, in randomized order, at concentrations of $10^{-8}$ to $10^{-4} \mathrm{M}$ with one of these drugs for a period of 15 minutes. There was a 20-minute drug-free washout period. Prior to this study we tested higher concentrations for each of these drugs. However, at concentrations higher than $10^{-3} \mathrm{M}$ some hearts showed cardiac arrest. Therefore, concentrations of $10^{-3} \mathrm{M}$ or more were not included in the present study.

The concentrations tested in our study $\left(10^{-8}\right.$ to $\left.10^{-4} \mathrm{M}\right)$, which are equivalent to 0.002 to $18 \mu \mathrm{g} / \mathrm{mL}$ propofol (molecular weight: $178.3 \mathrm{mM}$ ), 0.003 to $33 \mu \mathrm{g} / \mathrm{mL}$ midazolam (325.8 $\mathrm{mM}), 0.003$ to $27 \mu \mathrm{g} / \mathrm{mL} \mathrm{s}(+)$-ketamine (274.2 mM), 0.003 to $26 \mu \mathrm{g} / \mathrm{mL}$ methohexitone (262.3 mM), and 0.002 to $24 \mu \mathrm{g} / \mathrm{mL}$ etomidate $(244.3 \mathrm{mM})$, correspond to approximate therapeutic plasma-free values (corrected for plasma protein binding, in $\%$ ) of 5.1 to $11 \times 10^{-7}$ (97 to $98 \%$ ) propofol, 3.7 to $37 \times 10^{-9}$ M (94 to $95 \%)$ midazolam, 3.2 to $19 \times 10^{-6} \mathrm{M}(12$ to $30 \%)$

\section{Figure 1}

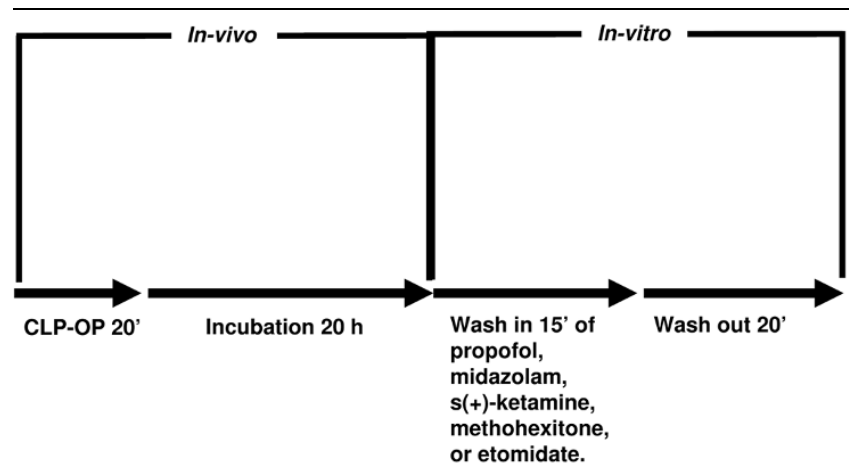

Study protocol. CLP-OP $=$ cecal ligation and puncture operating procedure. 
$\mathrm{s}(+)$-ketamine, 4.6 to $9.1 \times 10^{-6} \mathrm{M}(70$ to $73 \%)$ methohexitone, and 0.9 to $4.7 \times 10^{-7} \mathrm{M}(77$ to $94 \%)$ etomidate $[6,15,16]$. However, even higher concentrations up to 10 fold can easily be achieved by bolus injection [17].

\section{Statistical analysis}

All data in the text, tables and figures are displayed as means \pm standard error of the mean. Raw data from each functional and metabolic variable were compared by analysis of variance with repeated measures. If $\mathrm{F}$ tests were significant, Bonferoni tests were used to compare absolute group means for each variable measured at the same concentration and individual drug concentrations (and washout, WASH) against the initial control (CTRL). $P<0.05$ was considered to be statistically significant.

\section{Results}

Control values of sham-operated hearts (heart rate $309 \pm 4$ beats/min, LVP contractility (+dLVP/dt) $3275 \pm 84 \mathrm{mmHg} /$ $\mathrm{sec}$, LVP relaxation (-dLVP/dt) $2629 \pm 74 \mathrm{mmHg} / \mathrm{sec}$, cardiac work $36036 \pm 639 \mathrm{mmHg} /$ beats, and myocardial oxygen supply $\left(\mathrm{DO}_{2}\right)$ /myocardial oxygen consumption $\left(\mathrm{MVO}_{2}\right)$ ratio $1.5 \pm$ 0.0 were statistically different from control values of septic hearts. Sham-operated hearts showed control values of etomidate, $s(+)$-ketamine, midazolam, propofol, and methohexitone in septic hearts were not statistically different between the groups. After a washout period, each parameter returned to baseline level.

The comparative effects of etomidate, $s(+)$-ketamine, midazolam, propofol, and methohexitone on heart rate are shown in Figure 2. No effects on heart rate were observed at $1 \times 10^{-8}$ to $1 \times 10^{-6} \mathrm{M}$ for any induction agent. At higher concentrations, heart rate was significantly suppressed at $1 \times 10^{-4} \mathrm{M}$ for propofol (maximum decrease: $-29 \pm 4 \%$ ) and at $1 \times 10^{-5}$ to 1 $\times 10^{-4} \mathrm{M}$ for midazolam (maximum decrease: $-47 \pm 5 \%$ ). Reduction of heart rate by midazolam at $1 \times 10^{-4} \mathrm{M}$ was significantly more pronounced compared with all other tested induction agents. Maximum decreases in heart rate were -12 $\pm 3 \%$ for $\mathrm{s}(+)$-ketamine $\left(1 \times 10^{-4} \mathrm{M}\right)$ and $-11 \pm 4 \%$ for methohexitone $\left(1 \times 10^{-4} \mathrm{M}\right)$. Only etomidate showed no chronotropic effect at any tested concentration in this study.

All tested induction agents showed a dose-dependent decrease in cardiac contractility except for midazolam and $\mathrm{s}(+)$-ketamine (Figure 3 ). The maximum decrease in $+\mathrm{dLVP} / \mathrm{dt}$ of $-38 \pm 5 \%$ at $1 \times 10^{-4} \mathrm{M}$ and $-19 \pm 5 \%$ at $1 \times 10^{-4} \mathrm{M}$ was significant for propofol and methohexitone, respectively. The effects of propofol were significantly more pronounced compared with all other agents tested at equimolar concentrations. Other induction agents showed a maximum decrease in contractility of $-5 \pm 6 \%$ for etomidate at $1 \times 10^{-5} \mathrm{M}$, and a maximum increase in contractility of $+7 \pm 5 \%$ for $s(+)$-ketamine at $1 \times 10^{-4} \mathrm{M}$, and $+9 \pm 6 \%$ for midazolam at $1 \times 10^{-6} \mathrm{M}$. As shown in Figure 4, etomidate, midazolam, methohexitone, and propofol showed negative lusitropic effects with maximal decreases in -dLVP/dt of $-7 \pm 6 \%$ (at $1 \times 10^{-5} \mathrm{M}$, not significant), $-21 \pm 5 \%$ (at $1 \times 10^{-4} \mathrm{M}$, significant), $-21 \pm 6 \%$ (at $1 \times$ $10^{-4} \mathrm{M}$, significant), and $-44 \pm 5 \%$ (at $1 \times 10^{-4} \mathrm{M}$, significant), respectively. At $1 \times 10^{-4} \mathrm{M}$ the negative reduction of lusitropy by propofol was significantly different compared with all other tested induction agents. In contrast, at $1 \times 10^{-4} \mathrm{M} \mathrm{s}(+)$-ketamine demonstrated an increase in lusitropy of $+14 \pm 6 \%$. There was a significant difference compared with propofol and midazolam at equimolar concentration.

Cardiac work (Figure 5) - the product of LVP and heart rate was reduced at $1 \times 10^{-4} \mathrm{M}$ by etomidate (maximum decrease:

Figure 2

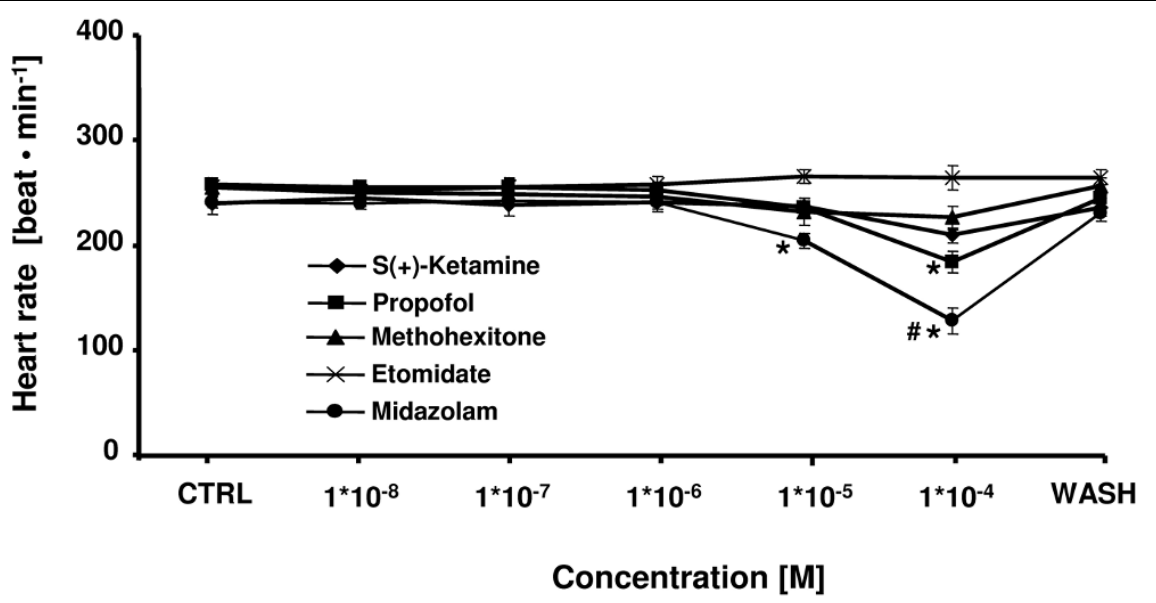

Comparative effects of etomidate, $\mathrm{s}(+)$-ketamine, midazolam, propofol, and methohexitone on heart rate in rat isolated septic hearts. All drugs except etomidate decreased chronotropic effects. For control values, only the first (CTRL) and the washout (WASH) periods are displayed. After the washout period, the heart rate returned to baseline level. ${ }^{*} P<0.05$ midazolam $\left(10^{-5}\right.$ to $\left.10^{-4} \mathrm{M}\right)$ and propofol $\left(10^{-4} \mathrm{M}\right)$ versus control; $\# P<0.05$ midazolam versus etomidate, $\mathrm{s}(+)$-ketamine, propofol, and methohexitone. Data are the means \pm standard error of the mean. 
Figure 3

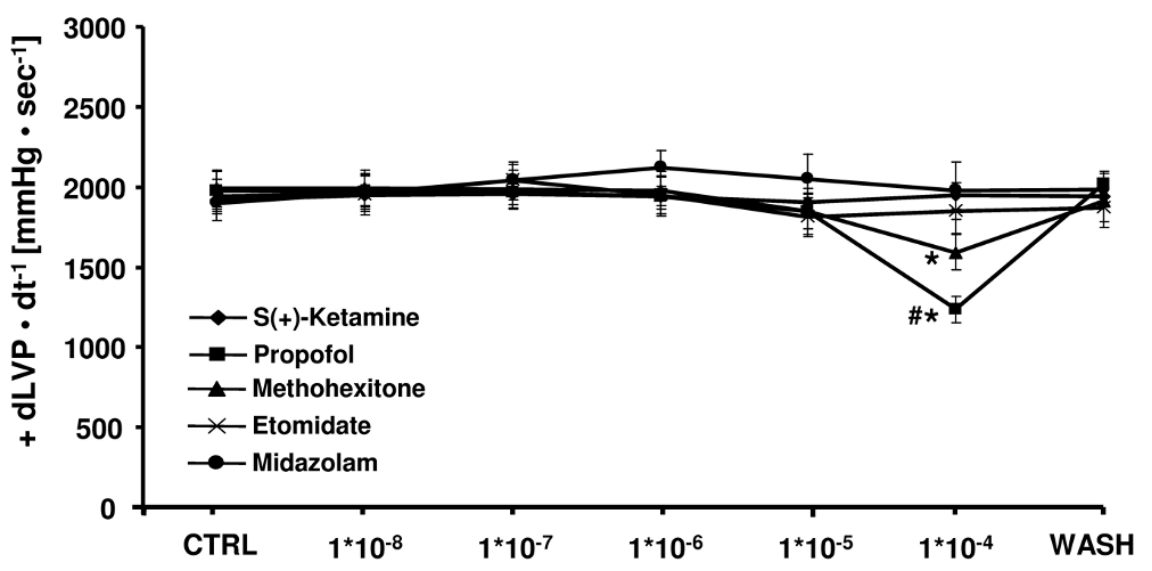

\section{Concentration [M]}

Comparative effects of etomidate, $\mathrm{s}(+)$-ketamine, midazolam, propofol, and methohexitone on left ventricular contractility in rat isolated septic hearts. All drugs except for $\mathrm{s}(+)$ ketamine and midazolam decreased contractility. For control values, only the first (CTRL) and the washout (WASH) periods are displayed. After the washout period, left ventricular contractility $\left(+\mathrm{dLVP}_{\mathrm{dt}}{ }^{-1}\right)$ returned to baseline level. ${ }^{*} P<0.05$ for methohexitone and propofol vs. control; $\# P<0.05$ propofol vs. etomidate, $s(+)$-ketamine, midazolam, and methohexitone. Data are the means \pm standard error of the mean.

$-17 \pm 6 \%)$, s(+)-ketamine $(-6 \pm 6 \%)$, midazolam $(-38 \pm 7 \%)$, propofol $(-50 \pm 6 \%)$, and methohexitone $(-31 \pm 4 \%)$ in a dosedependent fashion. At this concentration, the reduction of cardiac performance was significantly different for propofol, midazolam and methohexitone compared with $s(+)$-ketamine. Additionally, propofol significantly decreased cardiac work at $1 \times 10^{-5} \mathrm{M}$ by $-17 \pm 4 \%$.
Etomidate, $s(+)$-ketamine, midazolam, and methohexitone showed no direct effects on coronary flow, myocardial oxygen supply and demand (all not shown). Therefore, $\mathrm{DO}_{2} / \mathrm{MVO}_{2}$ ratio (Figure 6) was not affected by these agents. These effects were similar for propofol at $1 \times 10^{-8}$ to $1 \times 10^{-5} \mathrm{M}$. However, at $1 \times 10^{-4} \mathrm{M}$ propofol significantly increased coronary flow of $+29 \pm 4 \%$. Additionally, there was a considerable cardiac-work induced decrease in $\mathrm{MVO}_{2}$ and oxygen extraction, accompanied by a coronary flow dependent rise of $\mathrm{DO}_{2}$

Figure 4

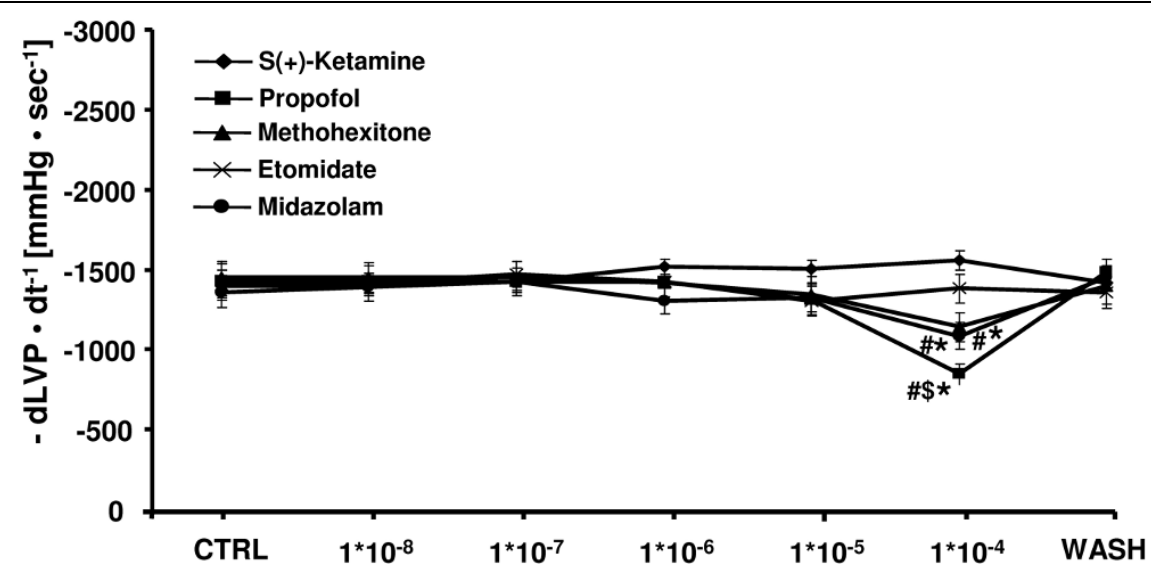

Concentration [M]

Comparative effects of etomidate, $\mathrm{s}(+)$-ketamine, midazolam, propofol, and methohexitone on left ventricular relaxation in rat isolated septic hearts. All drugs except for $s(+)$-ketamine decreased lusitropy. For control values, only the first (CTRL) and the washout (WASH) periods are displayed. After the washout period left ventricular relaxation $\left(-\mathrm{dLVP} / \mathrm{dt}^{-1}\right)$ returned to baseline level. ${ }^{*} P<0.05$ midazolam, propofol, and methohexitone vs. control; $\# P<0.05$ midazolam, propofol, and methohexitone vs. etomidate and $\mathrm{s}(+)$-ketamine; $\$ P<0.05$ propofol vs. midazolam and methohexitone. Data are the means \pm standard error of the mean. 


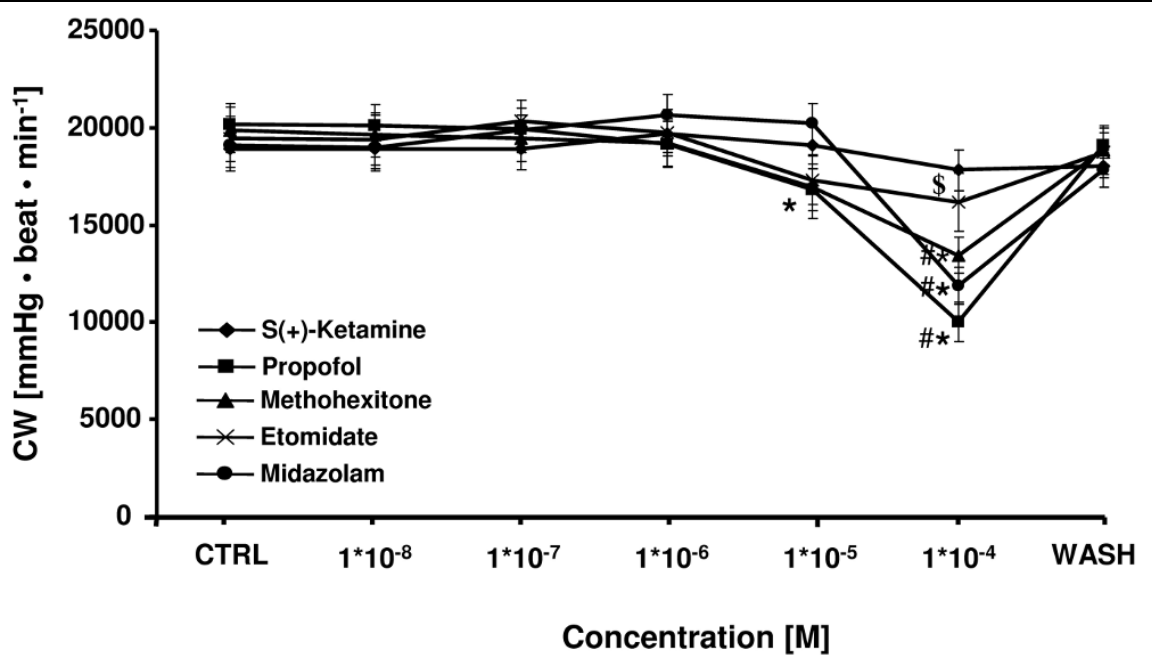

Comparative effects of etomidate, $\mathrm{s}(+)$-ketamine, midazolam, propofol, and methohexitone on cardiac work in rat isolated septic hearts. Each drug decreased cardiac work (CW). For control values, only the first (CTRL) and the washout (WASH) periods are displayed. After washout period CW returned to baseline level. ${ }^{*} P<0.05$ midazolam $\left(10^{-4} \mathrm{M}\right)$, propofol $\left(10^{-5}\right.$ to $\left.10^{-4} \mathrm{M}\right)$, and methohexitone $\left(10^{-4} \mathrm{M}\right)$ vs. control; $\#<<0.05$ midazolam and propofol vs. etomidate and methohexitone. $\$ P<0.05 \mathrm{~s}(+)$-ketamine vs. propofol, midazolam, and methohexitone. Data are the means \pm standard error of the mean.

leading to increase of $\mathrm{DO}_{2} / \mathrm{MVO}_{2}$ ratio (Figure 6) of $+58 \pm$ $4 \%$. This was significantly different compared with etomidate, $\mathrm{s}(+)$-ketamine, midazolam, and methohexitone at equimolar concentration.

\section{Discussion}

The study was designed to compare the direct effects of five commonly used intravenous induction agents by analyzing cardiac responses at equimolar concentrations in septic hearts.
The tested drugs demonstrate differential direct effects on electrical properties, myocardial function, andoxygen supplyto-demand ratio. Propofol showed the most pronounced adverse direct cardiac effects, whereas $s(+)$ ketamine was most beneficial, as it showed cardiac functionality over a wide range of concentration.

There are concerns regarding the application of etomidate in critically ill patients, especially in septic patients due to possi-

\section{Figure 6}

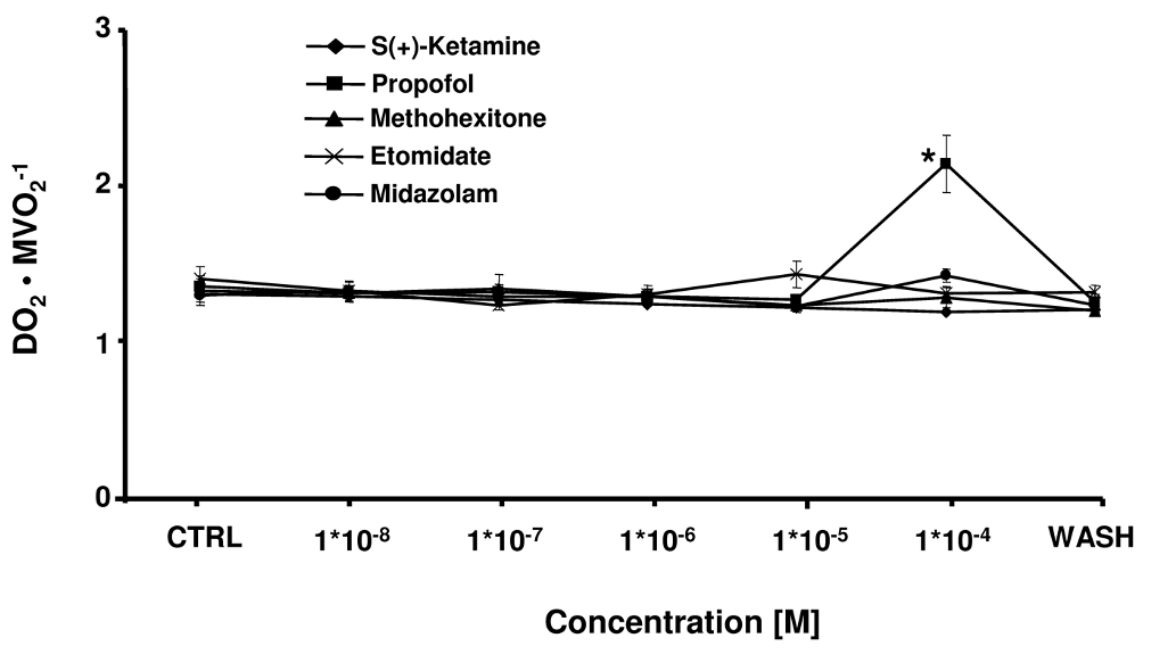

Comparative effects of etomidate, s(+)-ketamine, midazolam, propofol, and methohexitone on myocardial oxygen supply/myocardial oxygen consumption in rat isolated septic hearts. All drugs decreased myocardial oxygen supply/myocardial oxygen consumption $\left(\mathrm{DO}_{2} / \mathrm{MVO}_{2}{ }^{-1}\right)$ ratio. For control values, only the first (CTRL) and the washout (WASH) periods are displayed. After the washout period $\mathrm{DO}_{2} / \mathrm{MVO}_{2}{ }^{-1}$ returned to baseline level. ${ }^{*} P<0.05$ propofol vs. control, etomidate, $s(+)$-ketamine, midazolam, and methohexitone. Data are the means \pm standard error of the mean. 
ble adrenal suppression [18]. The incidence of this adrenal suppression in sepsis ranges from 9 to $67 \%$, and cortisol response to corticotrophin is more frequently impaired after administration of etomidate as compared with alternative induction agents [19]. However, in septic patients, cardiovascular instability is the main focus of clinicians because it is the major cause of morbidity and mortality in sepsis. The presence of cardiac dysfunction - demonstrated as septic cardiomyopathy - additionally decreases survival rate in septic patients [10]. Therefore, an induction agent that provides cardiovascular stability such as etomidate is frequently used in healthy subjects as it is intended to show minimal cardiovascular effects $[4,5]$. In the present study, we show that etomidate is safe with regard to cardiac function at concentrations of $10^{-8}$ to $10^{-5} \mathrm{M}$ in septic hearts. However, at higher concentrations it markedly depresses cardiac work. These concentrations can easily be achieved either by bolus administration or by long-term infusion in patients with severe sepsis or septic shock, especially with multiple-organ failure accompanied by a decreased hepatic and renal metabolism [20]. Therefore, these effects must be kept in mind, especially because other studies underline that a higher induction dose of etomidate is also associated with a decrease in systolic arterial blood pressure in animal models and patients with advanced age and heart disease [21].

In contrast, $s(+)$ ketamine showed cardiac functionality over a wide range of concentrations. $\mathrm{S}(+)$ ketamine is an optical isomer of ketamine and exhibits stereoselective bindings to different receptors, accounting for its three to four times higher anesthetic potency compared with the R(-)-isomer [16,22]. The racemic ketamine and both ketamine stereoisomers show negative chronotrope, dromotrope, and inotrope effects in the isolated healthy heart [22]. In septic hearts, $s(+)$ ketamine has no significant negative effect on LVP, contractility or lusitropy. This discrepancy might be explained by the fact that both the $\mathrm{R}(-)$-isomer and racemic ketamine in general show significantly more cardio-depressant effects as compared with the $S(+)$ isomer $[16,22]$. The mechanism behind this is a stereoselective suppression of the trans-sarcolemmal $\mathrm{Ca}^{2+}$ current $\left(\mathrm{ICa}^{2+}\right)$, which play an important role in the force of contraction and spontaneous firing of sinoatrial node cells, as demonstrated in electrophysiological experiments [23].

Midazolam and methohexitone, together with propofol, showed the most adverse effects on cardiac stability. Propofol, midazolam and methohexitone decreased cardiac work in a dose-dependent fashion. At very similar concentrations, Stowe and colleagues showed a decrease in contractility in guinea pig hearts from midazolam, propofol, and thiopental [6]. However, the degree of contractility reduction was more pronounced in healthy hearts as compared with septic ones. These surprisingly different results might be model or protocol dependent. Otherwise, as the mechanisms of the cardiac depressant effects of these induction agents is likely to involve attenuation of trans-sarcolemmal $\mathrm{Ca}^{2+}$ flux [6], the dysfunction of sarcoplasmic reticulum $\mathrm{Ca}^{2+}$ handling or altered calcium transient properties described in septic hearts might be attributable to these differing results $[24,25]$. The most striking finding on coronary flow was a direct vasodilating effect by propofol at $1 \times 10^{-4} \mathrm{M}$. This effect suggests that coronary autoregulation was inhibited at this concentration, and propofol may cause a substantial coronary vasodilation when used as an anesthetic induction agent $[6,13]$. In contrast, no other tested induction agent showed a direct vasodilating effect at any concentration. However, care has to be taken because depression of heart function is not always an expression of hazardous effects. For example, vasodilatation of the coronary arteries induced by propofol might have led to improving myocardial blood and oxygen supply as shown in Figure 6. Additionally, the slow down of the heart rate by midazolam might reduce myocardial energy demands, and may additionally improve diastolic filling of the heart.

We recognise the limitations of this study. Although the applied sepsis method has the advantages of inducing a 'natural' course of infection, it has limitations with regard to noteworthy outcome variability $[26,27]$. In contrast, other sepsis models, such as the bolus injection-type method, offer a simple and highly standardized method. However, failure of transmission of therapeutic results from bolus shock experiments into clinical use has emphasized that these models do not reflect all aspects of the sepsis syndrome [26]. In contrast, the cecal ligation and single puncture method is generally recognized as closely mimicing human disease by activating proand anti-inflammatory pathways. Another limitation of this study is that in addition to cardiac depression, induction agents also induce a systemic vascular dilatation that leads to hypotension. This is associated with an increased risk of death in critically ill patients [28]. However, the diagnosis of hypotension is easy, whereas the diagnosis of septic cardiomyopathy is more sophisticated and requires a more complex analysis. Therefore, at the moment of induction, this diagnosis may not be available, and septic patients would be at an increased risk in terms of choosing the wrong induction agent. On this account, we used an ex vivo approach and isolated hearts and focused on the direct cardiac effects of the applied induction agents. The advantages of this method are to measure mechanical and metabolic properties in the absence of the confounding effects of other organs, systemic circulation, and a host of peripheral complications such as circulating neurohormonal factors [29]. One potential limitation of an isolated heart preparation study is the possible influence of a force-frequency relationship. Although there are significant changes in heart rate for midazolam, which are not accompanied by a significant change in $+d L V P / d t$ (Figure 3 ) at $10^{-5} \mathrm{M}$, the possible influence of a force-frequency relationship has to be kept in mind when interpretating the presented results. 


\section{Conclusions}

In conclusion, this study showed that the tested drugs - etomidate, $s(+)$-ketamine, midazolam, propofol, and methohexitone - indeed have differential direct cardiac effects, even in the isolated septic heart. Propofol showed the most pronounced adverse direct cardiac effects, while $\mathrm{S}(+)$ ketamine demonstrated cardiac stability over a wide range of concentrations. Thus, if our data can be extrapolated to apply to humans, it seems that there are alternatives to etomidate such as $\mathrm{s}(+)$ ketamine, which demonstrates similar cardiac stability, but with less non-cardiovascular side effects affecting the outcome of septic patients.

\begin{tabular}{|l|}
\hline Key messages \\
- $\quad$ Induction agents show differential direct cardiac effects \\
in septic cardiomyopathy. \\
- $\quad$ propofol show most pronounced adverse effects. \\
- $\mathrm{S}(+)$ ketamine demonstrates cardiac stability over a \\
wide range of concentrations.
\end{tabular}

\section{Competing interests}

On behalf of my co-authors I attest that the work has not been funded by any source(s) other than described in the statement. No author or participant has any financial interest in the subject matter, materials or equipment discussed or in competing materials. The laboratory in which the research was performed has not been funded by, or has any participant in the planning, conduct, or reporting of the research been funded by or have financial interests in any source with a real or potential interest in the subject matter, materials, equipment or devices discussed or in any competing product or subject. And the laboratory in which the work was performed or any of the authors or participants have not been funded by any foundation or other non-governmental source that has received funding from any organization with a real or potential interest in the subject matter, materials, equipment or devices discussed, or in any competing product or subject.

\section{Authors' contributions}

$Y Z$ and $B G$ originated the idea and performed preliminary experiments. HB continued to perform the experiments. BS coordinated to the laboratory support. $Y Z$ and $W Z$ were responsible for writing the paper. $D L, B S$ and $B G$ supported the editing of the manuscript and added important comments to the paper. All authors read and approved the final manuscript.

\section{Authors' information}

The data was presented in part at the 3rd International Congress of the German Sepsis Society in Weimar from 5 to 8 September, 2007.

\section{Acknowledgements}

This study was supported with institutional funding from the Department of Anaesthesiology, University of Regensburg.

\section{References}

1. Dellinger RP, Levy MM, Carlet JM, Bion J, Parker MM, Jaeschke R, Reinhart K, Angus DC, Brun-Buisson C, Beale R, Calandra T, Dhainaut JF, Gerlach H, Harvey M, Marini JJ, Marshall J, Ranieri M, Ramsay G, Sevransky J, Thompson BT, Townsend S, Vender JS, Zimmerman JL, Vincent JL: Surviving Sepsis Campaign: international guidelines for management of severe sepsis and septic shock: 2008. Crit Care Med 2008, 36:296-327.

2. Reinhart $K$, Brunkhorst $F$, Bone $H$, Gerlach $H$, Grundling $M$, Kreymann G, Kujath P, Marggraf G, Mayer K, Meier-Hellmann A, Peckelsen C, Putensen C, Quintel M, Ragaller M, Rossaint R, Stuber F, Weiler N, Welte T, Werdan K: [Diagnosis and therapy of sepsis: guidelines of the German Sepsis Society Inc. and the German Interdisciplinary Society for Intensive and Emergency Medicine]. Anaesthesist 2006, 55(Suppl 1):43-56.

3. Malerba G, Romano-Girard F, Cravoisy A, Dousset B, Nace L, Levy $B$, Bollaert PE: Risk factors of relative adrenocortical deficiency in intensive care patients needing mechanical ventilation. Intensive Care Med 2005, 31:388-392.

4. Ray DC, McKeown DW: Effect of induction agent on vasopressor and steroid use, and outcome in patients with septic shock. Crit Care 2007, 11:R56.

5. McCollum JS, Dundee JW: Comparison of induction characteristics of four intravenous anaesthetic agents. Anaesthesia 1986, 41:995-1000.

6. Stowe DF, Bosnjak ZJ, Kampine JP: Comparison of etomidate, ketamine, midazolam, propofol, and thiopental on function and metabolism of isolated hearts. Anesth Analg 1992, 74:547-558

7. Parrillo JE: Myocardial depression during septic shock in humans. Crit Care Med 1990, 18:1183-1184.

8. Muller-Werdan U, Buerke M, Ebelt $H$, Heinroth KM, Herklotz $A$, Loppnow H, Russ M, Schlegel F, Schlitt A, Schmidt HB, Schmidt HB, Soffker G, Werdan K: Septic cardiomyopathy - A not yet discovered cardiomyopathy? Exp Clin Cardiol 2006, 11:226-236.

9. Fernandes $\mathrm{CJ} \mathrm{Jr}$, Akamine N, Knobel E: Myocardial depression in sepsis. Shock 2008, 30(Suppl 1):14-17.

10. Merx MW, Weber C: Sepsis and the heart. Circulation 2007 , 116:793-802.

11. Krishnagopalan S, Kumar A, Parrillo JE: Myocardial dysfunction in the patient with sepsis. Curr Opin Crit Care 2002, 8:376-388.

12. Zink W, Kaess M, Hofer S, Plachky J, Zausig YA, Sinner B, Weigand MA, Fink RH, Graf BM: Alterations in intracellular Ca2+homeostasis of skeletal muscle fibers during sepsis. Crit Care Med 2008, 36:1559-1563.

13. Zausig YA, Stowe DF, Zink W, Grube C, Martin E, Graf BM: A comparison of three phosphodiesterase type III inhibitors on mechanical and metabolic function in guinea pig isolated hearts. Anesth Analg 2006, 102:1646-1652.

14. Stowe DF, Graf BM, Fujita S, Gross GJ: One-day cold perfusion of bimakalim and butanedione monoxime restores ex situ cardiac function. Am J Physiol 1996, 271:H1884-1892.

15. Heck M, Fresenius M: Repetitorium Anaesthesiologie. 5th edition. Heidelberg: Springer; 2007.

16. Sinner B, Graf BM: Ketamine. Handb Exp Pharmacol 2008:313-333.

17. Johnson KB, Egan TD, Kern SE, McJames SW, Cluff ML, Pace NL: Influence of hemorrhagic shock followed by crystalloid resuscitation on propofol: a pharmacokinetic and pharmacodynamic analysis. Anesthesiology 2004, 101:647-659.

18. Annane $D$ : ICU physicians should abandon the use of etomidate! Intensive Care Med 2005, 31:325-326.

19. Absalom A, Pledger $D$, Kong $A$ : Adrenocortical function in critically ill patients $24 \mathrm{~h}$ after a single dose of etomidate. Anaesthesia 1999, 54:861-867.

20. Johnson KB, Egan TD, Kern SE, White JL, McJames SW, Syroid N, Whiddon $D$, Church T: The influence of hemorrhagic shock on propofol: a pharmacokinetic and pharmacodynamic analysis. Anesthesiology 2003, 99:409-420. 
21. Shirozu K, Akata T, Yoshino J, Setoguchi H, Morikawa K, Hoka S: The mechanisms of the direct action of etomidate on vascular reactivity in rat mesenteric resistance arteries. Anesth Analg 2009, 108:496-507.

22. Graf BM, Vicenzi MN, Martin E, Bosnjak ZJ, Stowe DF: Ketamine has stereospecific effects in the isolated perfused guinea pig heart. Anesthesiology 1995, 82:1426-1437. discussion 1425A

23. Sekino N, Endou M, Hajiri E, Okumura F: Nonstereospecific actions of ketamine isomers on the force of contraction, spontaneous beating rate, and $\mathrm{Ca} 2+$ current in the guinea pig heart. Anesth Analg 1996, 83:75-80.

24. Hassoun SM, Marechal X, Montaigne D, Bouazza Y, Decoster B Lancel S, Neviere R: Prevention of endotoxin-induced sarcoplasmic reticulum calcium leak improves mitochondrial and myocardial dysfunction. Crit Care Med 2008, 36:2590-2596.

25. Ren J, Ren BH, Sharma AC: Sepsis-induced depressed contractile function of isolated ventricular myocytes is due to altered calcium transient properties. Shock 2002, 18:285-288.

26. Freise H, Bruckner UB, Spiegel HU: Animal models of sepsis. $J$ Invest Surg 2001, 14:195-212.

27. Hubbard WJ, Choudhry M, Schwacha MG, Kerby JD, Rue LW 3rd, Bland KI, Chaudry IH: Cecal ligation and puncture. Shock 2005, 24(Suppl 1):52-57.

28. Leibowitz $A B$ : Tracheal intubation in the intensive care unit: extremely hazardous even in the best of hands. Crit Care Med 2006, 34:2497-2498.

29. Graf BM, Abraham I, Eberbach N, Kunst G, Stowe DF, Martin E: Differences in cardiotoxicity of bupivacaine and ropivacaine are the result of physicochemical and stereoselective properties. Anesthesiology 2002, 96:1427-1434. 